OPEN ACCESS

Edited by:

Ferit Tuzer,

Drexel University, United States

Reviewed by:

Kathryn G. Todd,

University of Alberta, Canada

Jenna Ziebell,

University of Tasmania, Australia

${ }^{*}$ Correspondence:

Min-Soo Kwon

minsoo100@cha.ac.kr

Specialty section:

This article was submitted to Cellular and Molecular Mechanisms of Brain-aging,

a section of the journal

Frontiers in Aging Neuroscience

Received: 28 August 2021

Accepted: 06 December 2021

Published: 05 January 2022

Citation:

Yoo H-J and Kwon M-S (2022) Aged Microglia in Neurodegenerative

Diseases: Microglia Lifespan and Culture Methods.

Front. Aging Neurosci. 13:766267.

doi: 10.3389/fnagi.2021.766267

\section{Aged Microglia in Neurodegenerative Diseases: Microglia Lifespan and Culture Methods}

\author{
Hyun-Jung Yoo ${ }^{1,2}$ and Min-Soo Kwon ${ }^{1 *}$ \\ ${ }^{1}$ Department of Pharmacology, School of Medicine, Research Institute for Basic Medical Science, CHA University, Cha Bio \\ Complex, Seongnam-si, South Korea, ${ }^{2}$ Research Competency Milestones Program (RECOMP) of School of Medicine, CHA \\ University, Seongnam-si, South Korea
}

Microglia have been recognized as macrophages of the central nervous system (CNS) that are regarded as a culprit of neuroinflammation in neurodegenerative diseases. Thus, microglia have been considered as a cell that should be suppressed for maintaining a homeostatic CNS environment. However, microglia ontogeny, fate, heterogeneity, and their function in health and disease have been defined better with advances in singlecell and imaging technologies, and how to maintain homeostatic microglial function has become an emerging issue for targeting neurodegenerative diseases. Microglia are long-lived cells of yolk sac origin and have limited repopulating capacity. So, microglial perturbation in their lifespan is associated with not only neurodevelopmental disorders but also neurodegenerative diseases with aging. Considering that microglia are longlived cells and may lose their functional capacity as they age, we can expect that aged microglia contribute to various neurodegenerative diseases. Thus, understanding microglial development and aging may represent an opportunity for clarifying CNS disease mechanisms and developing novel therapies.

Keywords: microglia, aging, neurodegenerative diseases, microglia lifespan, microglia culture

\section{INTRODUCTION}

Microglia were recognized as a type of connective tissue or passive bystander of the central nervous system (CNS) physiology for a century since their discovery by Pio del Rio Hortega in 1919. Nowadays, microglia are defined as multifunctional cells that communicate with the peripheral system as well as other CNS cells, such as neurons, astrocytes, and oligodendrocytes, in physiological states. In addition, microglia are not considered as just spectators in CNS pathologies and have been found to play roles as determinants of diseases.

\section{MICROGLIA DEVELOPMENT AND AGING}

\section{Microglia Development and Specific New Markers}

Microglia are the primary innate immune cells located within CNS parenchyma and have different unique signature genes from other CNS macrophages, such as perivascular macrophage, meningeal macrophage, and choroid plexus macrophage (Li and Barres, 2018). In addition, microglia develop 
in a stepwise fashion (Matcovitch-Natan et al., 2016), indicating that prenatal and postnatal microglia are different from adult microglia.

One of the reasons microglia can have unique signature genes is associated with their origin and developmental process. Owing to phenotypic similarities to dendritic cells (DCs) and peripheral monocytes/macrophages, the origin of microglia was presumed to be of hematopoietic origin. In fact, many studies have supported this speculation, showing that irradiationinduced myeloablation facilitates infiltration of Ly-6C ${ }^{\text {hi CCR2 }}{ }^{+}$ monocytes into CNS (Mildner et al., 2007; Varvel et al., 2012). These data suggest that peripheral monocytes can migrate to CNS parenchyma and settle down with morphological similarities to microglia. However, this occurred only under factitious conditions, and there was no way to confirm whether the engrafted monocytes are truly resident microglia. Meanwhile, Ginhoux et al. (2010) clearly proved that microglia were derived from embryonic yolk sac during development by using in vivo fate mapping approach for yolk-sac-derived cells. This observation was confirmed again by Schulz et al. (2012), who showed that $\mathrm{Myb}^{-/-}$mice had a normal number of microglia but were deficient in hematopoietic-derived monocytes/macrophages. Conclusively, microglia are derived from the first wave of hematopoiesis in the yolk sac and not from postnatal hematopoiesis (Ajami et al., 2007). To summarize the overall development of microglia, microglia precursors derived from yolk sac migrate to the brain parenchyma at embryonic day 8.5 (E8.5) in mice (Nayak et al., 2014) and gestational week 12-13 (GW12-13) (Lloyd et al., 2017) in humans and then proliferate and acquire the ramified form through their developmental program, resulting in having their signature genes (developing microglia column in Figure 1). The mature form of microglia contributes to CNS homeostasis by interacting with almost all CNS components as well as the peripheral immune system. In healthy state, microglia dynamically survey the surrounding environment and maintain steady, region-specific densities by self-renewal.

After confirming microglial origin, essential factors for microglia development and maintenance have been suggested in various mutant mice ( $\mathrm{Li}$ and Barres, 2018). Macrophage colony-stimulating factor (M-CSF or CSF1) is a hematopoietic growth factor produced by endothelial cells, microglia, oligodendrocytes, and astrocytes in CNS and induces differentiation, proliferation, and maturation of macrophages. CSF1 receptor (CSF1R), a receptor tyrosine kinase with two cognate ligands [CSF-1 and interleukin-34 (IL-34)], regulates tissue macrophage homeostasis (Chitu et al., 2016). Recent studies in mice have revealed that CSF1R signaling contributes to the development and maintenance of the microglial population. In CSF1R-mutant mice, yolk-sac macrophages were absent and microglia colonization failed to occur (Oosterhof et al., 2018). Similarly, PLX3397 (CSF1R inhibitor) administration for 7 days eliminates $>90 \%$ of microglia in adult mice (Elmore et al., 2014). Consistently, microglia-specific Csflr knockout (KO) mice also showed loss of microglia (Buttgereit et al., 2016). Interleukin-34 ablation in neuronal progenitors led to the loss of gray matter microglia in a selective, dose-dependent manner (Badimon et al.,
2020). In addition, reports have shown that the development of microglia also relies on the transcription factors interferon regulatory factor 8 (IRF8) and PU.1 (Kierdorf et al., 2013). The cytokine transforming growth factor- $\beta$ (TGF- $\beta$ ), known as an anti-inflammatory cytokine, is another important factor in the development of microglia and in maintaining the homeostatic function of microglia (Butovsky et al., 2014).

The clarified microglial origin indicates that microglia can have their unique characters distinct from the neuroectodermal origin of other CNS cells. Nevertheless, researchers had no means to detect resident microglia, except for markers such as ionized calcium-binding adaptor molecule (Iba-1), fractalkine receptor [CX3C chemokine receptor 1 (CX3CR1)], and $\mathrm{CD} 11 \mathrm{~b}$ that are also expressed by CNS-engrafted monocytes/macrophages (Kettenmann et al., 2011). Thus, the absence of microglia-specific markers made it difficult to interpret the role of microglia under the complex neuroinflammatory environment formed by a mixture of microglia and CNS-engrafted monocytes/macrophages. For example, it was almost impossible to distinguish whether core cells of the neuroinflammatory response in multiple sclerosis were resident microglia or engrafted immune cells that permit infiltration of peripheral immune cells into CNS parenchyma. Considering that neuroinflammation is not uniform and has a diverse status, the aforementioned conundrum also applies to other neurological disorders, such as stroke, Alzheimer's disease (AD), Parkinson's diseases, amyotrophic lateral sclerosis (ALS), and psychiatric disorders (Rezai-Zadeh et al., 2009; Takahashi et al., 2016; Yang et al., 2020).

The abovementioned concerns have been resolved by the discovery of purinergic receptor P2Y12 (P2RY12) in 2014 (Butovsky et al., 2014) and transmembrane protein 119 (TMEM119) in 2016 (Bennett et al., 2016). Before the discovery of these markers, morphological distinctions, relative marker expression (of the common leukocyte antigen $\mathrm{CD} 45^{h i / l o}$ ) by flow cytometry, or generating bone marrow (BM) chimeras were used to distinguish microglia from engrafted CNS macrophages and peripheral monocytes (Lassmann et al., 1993; Ford et al., 1995). These techniques presented inherent limitations as these are not unique markers and the chimera model leads to partial chimerism, requiring much effort and time. Meanwhile, with advanced techniques, such as genetics, imaging, mass spectrometry, single-cell technologies, and transcriptome analysis, it has become possible to elucidate the heterogeneity and functional role of microglia in mice and humans. Establishment of CX3CR1CreER mouse lines to target microglia (Goldmann et al., 2013; Yona et al., 2013), identification of a microgliaspecific signature using transcriptome analysis (Beutner et al., 2013; Butovsky et al., 2014), identification of microglial heterogeneity and subpopulation depending on brain region (Grabert et al., 2016), sex (Guneykaya et al., 2018; Villa et al., 2018), and neurodegenerative disease using single-cell analysis of murine and human microglia are the examples. Regarding validation of microglia-specific antibody, P2RY12 immunoreactivity (IR) for resident microglia was not colocalized with green fluorescent protein (GFP)-tagged infiltrated monocytes in experimental autoimmune encephalomyelitis 


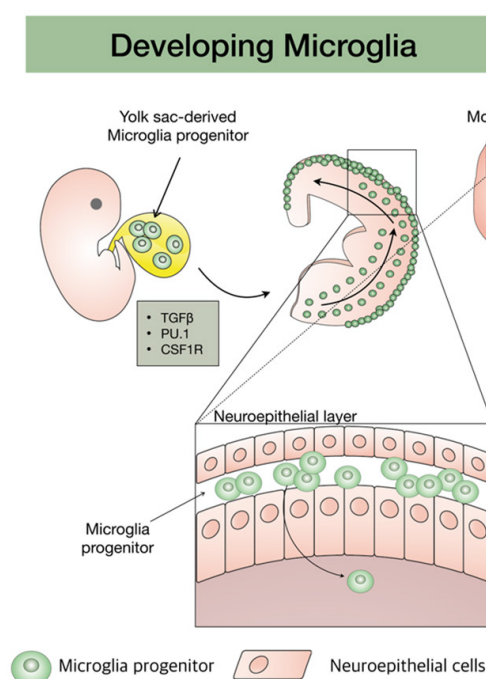

\section{Synaptic pruning}

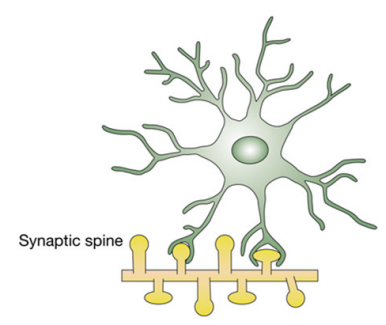

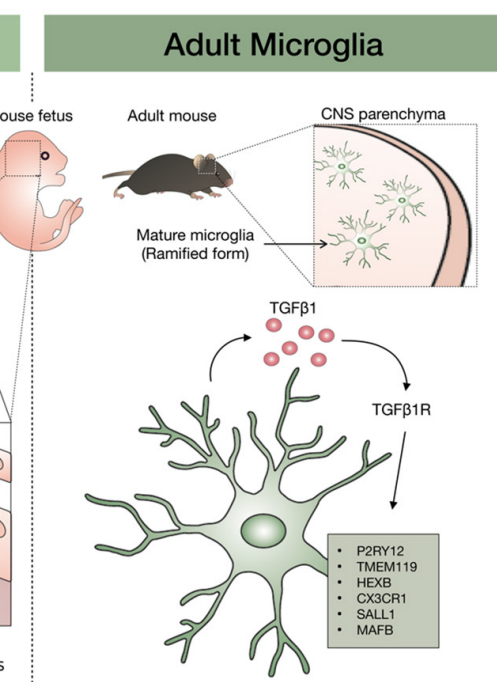
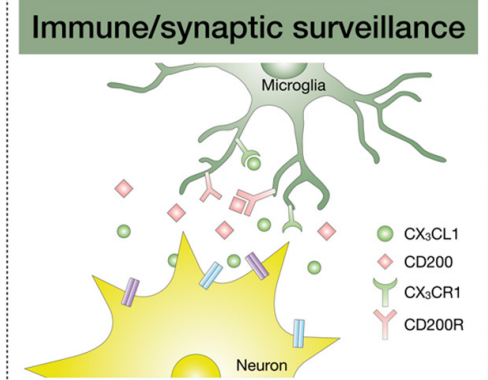
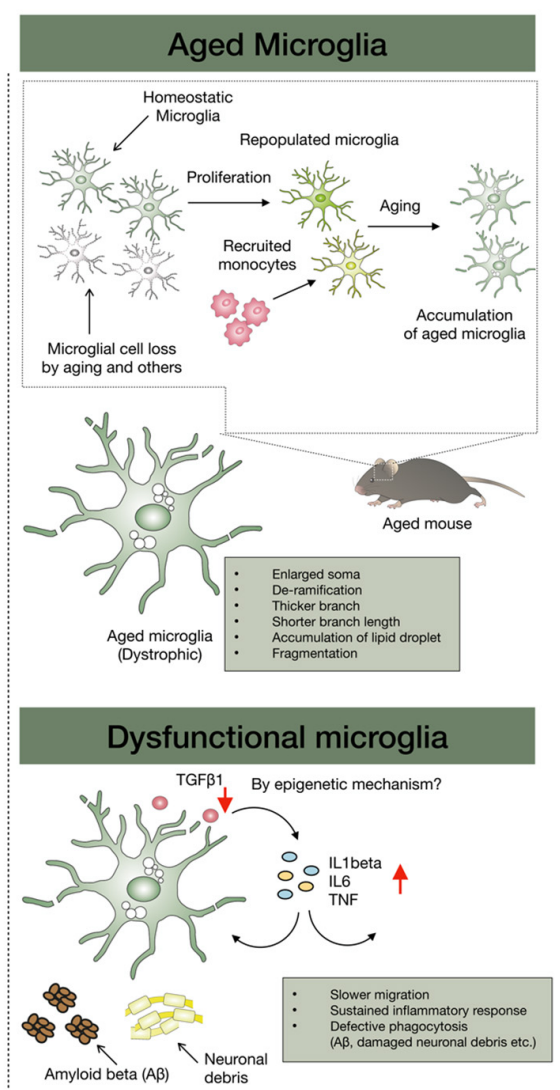

FIGURE 1 | Microglial development, repopulation, and aging. Microglia progenitors are originated from the yolk sac and migrate to the brain parenchyma through the head neuroepithelial layer, and then proliferate and acquire the ramified form with adult microglial signatures. TMEM119, P2RY12, CX3CR1, and HEXB are signature genes on adult microglia, and TGF- $\beta$ plays a crucial role in their maintenance. With aging, microglial loss can occur and the loss might be replaced by microglial proliferation or infiltrated macrophages distinct from the yolk-sac origin of homeostatic microglia. However, owing to limited repopulating capacity, it is speculated that aged microglia can be accumulated in the aged brain, leading to entire work overload due to relative dysfunctional aged microglia. The epigenetics might be involved in the alteration of homeostatic microglial genes in aged microglia.

(EAE) model with demyelinated pathology by infiltrated immune cells (Butovsky et al., 2014). In mutant superoxide dismutase 1 (mSOD1) mice, P2RY12 IR was rarely detected in the end stage of disease, although many Iba-1-positive cells were co-localized with increased inducible nitric oxide synthase (iNOS) in the spinal cord. Another microglia-specific marker, TMEM119, plays a key role in the validation of the microglial cell model as a signature gene that is expressed only in adult microglia (Bennett et al., 2016). After confirming microglia-specific markers, cell models closer to adult microglia, which can also be known as "microglia-like cells," have been reported (adult microglia column in Figure 1). This issue is going to be introduced in section "in vitro Methods for Aged Microglia Study." Collectively, these newly derived markers raise the fundamental question about the role of resident microglia during neuroinflammation and disease progression, and this issue is going to be discussed in section "Aged Microglia in Neurodegenerative Diseases."

\section{The Origin of Repopulated Microglia}

As mentioned above, microglia originate from the yolk sac and not the neuroectoderm. Therefore, we have no choice but to ask the next question. How are microglia replaced if microglial cells are depleted by aging or other stimuli? The possible hypothesis that microglia loss would be supplemented by BM-derived monocytes seems to be reasonable. Acute microglia depletion by pharmacological inhibition via CSF1R antagonist induced peripheral monocytes infiltration into CNS without blood-brain barrier (BBB) breakdown, and the infiltrated monocytes showed functional behavior like resident microglia, although transcriptome analysis revealed that the replaced cells did not have the same signature genes as that of resident microglia (Cronk et al., 2018). However, there is a report that acute depletion of microglia could be repopulated by the proliferation of residual microglia rather than de novo microglia progenitor differentiation, nestin-positive cells, or peripheral monocytes/macrophages (Huang et al., 2018). However, this study also indicated that transcriptomes of the repopulated microglia were distinct from resident microglia. The debate on the origin of repopulated microglia is still ongoing, but two major studies have a common finding that the repopulated microglia are not the same as yolk-sac-derived resident microglia. This finding is very important since microglia aging may be associated 
with various neurological disorders (aged microglia column in Figure 1) (Spittau, 2017; Angelova and Brown, 2019). In addition, a heterogeneous population of aged microglia might require a stratified targeting for microglia rejuvenation strategy.

\section{Microglia Lifespan and Limited Repopulation}

Microglia are long-lived cells, and their activities may be dysregulated as they age. In addition, microglia are not replenished by circulating monocytes under homeostatic conditions (Mildner et al., 2007). As mentioned above, microglia can be replenished by repopulation when depleted, but the repopulated microglia are not the same transcriptionally as previous resident microglia. Thus, microglia lifespan is a crucial point in understanding the pathophysiology of neurological disorders. Previously, an indirect study to establish chimerism in circulating BM-derived precursors suggested that microglia lived long in healthy CNS through much of the lifespan of an animal (Mildner et al., 2007). More recently, by in vivo single-cell imaging, it was found that the median lifetime of neocorticalresident microglia was over 15 months, and approximately half of total microglia survived the entire mouse lifespan, suggesting that microglia are long-lived cells and microglial replenishment may be less required relatively than other CNS cells (Fuger et al., 2017). In humans, an indirect method referring to the ${ }^{14} \mathrm{C}$ atmospheric curve was used to analyze the lifespan and turnover of microglia. Human microglia renewed at a median rate of $28 \%$ per year and the average lifespan was 4.2 years. Most of the microglia population (96\%) was renewed throughout life, suggesting that the microglia population in the human brain is maintained by persistent slow turnover throughout adult life (Reu et al., 2017). Thus, the persistence of individual microglia throughout life explains how microglial aging may contribute to age-related neurodegenerative diseases.

Is endless repopulation of adult microglia possible? Adult microglia can be depleted by $90 \%$ by CSF1R inhibitor in mice. Once microglia are depleted acutely, withdrawal of inhibitor promotes repopulation of microglia in the entire CNS, and greater depletion of microglia results in more rapid repopulation (Najafi et al., 2018). Interestingly, this study found that the recovery time was gradually extended as the depletion was repeated, indicating the possible limited capacity for microglial repopulation. Thus, maintaining yolk-sac-derived microglia in a healthy state for a long time can be a good strategy to prevent age-related neurodegenerative diseases.

\section{Aged Microglia in Neurodegenerative Diseases}

Aging is associated with altered inflammatory status in the brain as well as systemically. As CNS ages, microglial morphology and number also change. Aged microglia in humans demonstrate dystrophic morphologies, indicating fragmentation of residual processes, less branching, deramified dendritic arbors, and cytoplasmic beading in shape relative to young microglia depending on the observed region (Streit et al., 2004). The dystrophic microglia are contrasted morphologically and functionally with dark microglia showing the condensation of their cytoplasm and nucleoplasm, accompanied by cytoplasm shrinkage, Golgi apparatus, and endoplasmic reticulum dilation, highly ramified morphology, and increased phagocytosis (Bisht et al., 2016). Along with this morphological change, homeostatic microglial functions decline with aging. Homeostasis is defined as a relative constancy of set point formed in certain conditions, and maintaining homeostatic microglial function indicates an effort to restore the deviating set point due to aging in the CNS environment (Deczkowska et al., 2018). The homeostatic microglial function indicates timely proper response required at each stage of life. Because excessive or tolerant microglial response can interrupt the tissue restoration after CNS damage, the transition from homeostatic microglial function in steady-state to immune-modulating mode under pathological conditions should be tightly regulated. Hence, microglial immune checkpoints, which are a set of controlling mechanisms preventing uncontrolled response in microglia, were suggested (Deczkowska et al., 2018). CX3CR1, also known as the fractalkine receptor, is a transmembrane protein and chemokine for leukocyte migration expressed on monocytes, DCs, and microglia (Harrison et al., 1998). CX3CL1, a ligand of CX3CR1, is expressed on the neuronal surface or released as the active soluble form from specific neurons. Tight regulation between neuronal CX3CL1 and microglial CX3CR1 controls microglial functional phenotype and their hyperactivation under an inflammatory environment. For example, CX3CR1 deficiency in mice with an induced exaggerated response to lipopolysaccharide (LPS) stimuli in CNS showed microglial neurotoxicity and advanced neuronal death (Cardona et al., 2006b). CD200 receptor (CD200R) in microglia also interacts with neighboring cells, including neurons, astrocytes, oligodendrocytes, and endothelial cells through their CD200 ligand; this has also been suggested as a mechanism of attenuating microglial activation, primarily under inflammatory conditions (Walker and Lue, 2013).

Another homeostatic transcriptional regulator of microglia is TGF- $\beta$ produced by astrocytes and microglia at high levels in healthy CNS (Butovsky and Weiner, 2018). TGF- $\beta$ KO microglia show aberrant immune-activated signature, increased neuronal death, reduced synaptic plasticity, and late-onset motor deficits (Brionne et al., 2003). Transcription factors (MafB, Mef2C, and Sall1) and MeCP2 as a methylated DNA binding repressor are also involved in controlling microglial immune activity. Congenital disruption of the MafB gene in microglia induced enhanced inflammation in adult mice (Matcovitch-Natan et al., 2016). Mef2C, which is expressed in microglia, limited microglial immune activation in response to pro-inflammatory perturbations (Potthoff and Olson, 2007). $\mathrm{MeCP} 2$ also aggravates immune response to tumor necrosis factor (TNF) (Cronk et al., 2015). Sall1, which controls the transcriptional signature of microglia, regulates microglial identity and physiological features in the CNS (Buttgereit et al., 2016). In this study, Sal1 deficiency in microglia induced their activation and disturbed adult hippocampal neurogenesis.

As described above, changes in several immune checkpoints can affect microglial homeostatic function that is orchestrated by checkpoint mechanisms throughout life. Interestingly, microglial 
immune checkpoints are distorted with aging, indicating dysregulation of homeostatic microglial function (Deczkowska et al., 2018). Aged microglia display increased immune vigilance (high expression of both immunoreceptors and an inflammatory secretome) along with dysregulated phagocytosis (Grabert et al., 2016). The increased release of neurotoxic substances and reduced ability to phagocytose debris and toxic protein aggregates in dystrophic microglia leaves neurons vulnerable. Insufficient phagocytic activity of aged microglia toward apoptotic bodies, misfolded protein aggregates, and myelin might result in the gradual accumulation of potentially toxic compounds, a hallmark of age-related neurodegenerative diseases (Safaiyan et al., 2016; Galloway et al., 2019; Damisah et al., 2020). The cause of such phenotypic shift in aged microglia appears to be related with changes in the microglial homeostatic gene profile. In essence, directly isolated microglia from aged human brain also support the observation that aged human microglia exhibit downregulated TGF- $\beta$ signaling in Kyoto Encyclopedia of Genes and Genomes (KEGG) pathway (Olah et al., 2018). This report suggests that diminishing TGF- $\beta$ signaling highlights the perturbation of homeostatic programs as microglia activate reactive pathways to respond to aging-related changes such as the accumulation of amyloid pathology. Another study using cortical microglia purified from postmortem human samples clearly demonstrated aged microglia-associated gene profiles such as cell surface receptor P2RY12 and cell adhesion molecules (Galatro et al., 2017). Microglial functional phenotype can be regulated by TGF- $\beta$ produced by astrocytes and neurons among other cells (von Bernhardi and Ramirez, 2001; Chen et al., 2002; Herrera-Molina and von Bernhardi, 2005). TGF- $\beta$ promotes phagocytosis and neuronal protection, depending on the Smad3-mediated mechanism in microglia (Tichauer et al., 2014; von Bernhardi et al., 2015). Thus, aging or loss of the TGF- $\beta$ releasing cells might affect microglial TGF- $\beta$ signaling and their homeostatic genes expression. Changes in gene expression in aged microglia may also be based on changed epigenetics. Microglia plasticity can be controlled by epigenetics (Cheray and Joseph, 2018), and aged microglia show upregulation of $I L-1 \beta$ gene expression by hypomethylation of CpGs sites on $I L-1 \beta$ proximal promoter (Matt et al., 2016). Similarly, a unique epigenome and transcriptome can define a phenotype of microglia in aging, including changes in homeostatic microglial genes such as TGF- $\beta, C X 3 C R 1$, and P2RY12.

Along with extreme longevity (Fuger et al., 2017) and limited repopulation capacity (Najafi et al., 2018) of microglia, turnover of aged microglia does not reset the pro-inflammatory phenotype in the aged CNS microenvironment (O'Neil et al., 2018). In addition, the homeostatic microglia population gradually decreases with aging (Niraula et al., 2017), leading to work overload for the remaining microglia. Thus, an intrinsic dysfunction of aged microglia is closely related to neurodegenerative disease. "Dystrophic microglia" refers to microglial morphological changes with age (Streit and Xue, 2014); they have been detected in the periphery of tau and amyloid pathology in the brains of patients with $\mathrm{AD}$ and likewise near sites of Lewy bodies in the brain of patients with dementia with Lewy bodies (Streit and Xue, 2016; Shahidehpour et al., 2021). In particular, microglia activation occurs at the early stages of $\mathrm{AD}$, and as it disappears, microglia become senescent/dystrophic and less responsive to stimuli at a late stage (Graeber and Streit, 2010). Histopathological finding from 19 AD pathologies indicates that aging-related microglial degeneration rather than microglial activation might contribute to the onset of $\mathrm{AD}$ (Streit et al., 2009). In fact, aged microglia-related releasing factors disturbed clearance of apoptotic bodies and aggregation of $\alpha$-synuclein, thus, aggravating disease progression (Angelova and Brown, 2019). In mSOD1 mice, which is a familial ALS mouse model, microglia were involved in inflammatory reactions in the early stage, and they exhibited a tolerant and dystrophic form that does not function properly at the end stage of disease progression, demonstrating P2RY12 IR disappearance, despite Iba-1 IR increase in the spinal cord (Butovsky et al., 2015). Similarly, acutely isolated mSOD1 microglia in the symptomatic period showed $\beta$-galactosidase activity as well as the elevation of p16, matrix metalloproteinase-1 (MMP-1), p53, and nitrotyrosine with large and flat morphology, suggesting a senescence-associated secretory phenotype (SASP) (Trias et al., 2019). Chronic amyloid $\beta$ exposure induced microglial impairment with immune tolerance, which was associated with microglial metabolic defects (downregulation of mTORglycolysis pathways) (Baik et al., 2019). Chronic stress, which is an aggravating factor in $\mathrm{AD}$ and risk factor in mood disorders, also sensitized microglia toward a primed phenotype in the acute stage, and, subsequently, led to dystrophic morphology according to stress duration in mice, suggesting that chronic depression may be associated with dystrophic microglia (Kreisel et al., 2014).

At this point, one question is why multiple studies thus far have suggested that inflammatory activation of microglia is the main culprit of neurodegenerative diseases, although microglia have dystrophic morphology and lose their homeostatic genes. One of the main causes is associated with previous microglial markers such as Iba-1 and CD11b that cannot discriminate resident microglia from infiltrated monocytes/macrophages because microglia signature genes, including P2RY12 and TMEM119, were established after 2014 as mentioned above. Thus, papers published before 2014 seem to have mistaken the main culprit for the neuroinflammatory response as resident microglia rather than Iba-1- (or other previous markers) positive cells, detecting both infiltrated monocyte/macrophages and resident microglia in neurodegenerative diseases with BBB breakdown. Another possible reason is related to immature features of fetal or neonatal microglial cells, widely used as in vitro surrogates. Single-cell analysis according to developmental state clearly identified that fetal/neonatal microglial cells had a different signature from acute-isolated adult microglia in mice (Matcovitch-Natan et al., 2016), and microglial cell lines, as well as fetal/neonatal microglial cells, rarely express adult microglial signature genes (Butovsky et al., 2014). Regarding microglial functional character, acute-isolated microglia from post-mortem human brain tissue showed a tightly regulated phenotypic change to an inflammatory environment composed of LPS and interferon- $\gamma($ IFN- $\gamma)$ compared with neonatal/fetal microglia (Melief et al., 2012). Thus, we cannot exclude the possibility that immature microglial cells present more dynamic 
inflammatory reactions to inflammatory stimuli distortions than actual adult microglia. Based on these reports, it may be concluded that the responsibility for neuroinflammation in neurodegenerative diseases cannot be shifted only to the yolk-sac origin of homeostatic microglia rather than infiltrated monocyte/macrophages because dystrophic and tolerant microglia were also observed in most neurodegenerative diseases (Streit et al., 2009; Varvel et al., 2016; Karlen et al., 2018; Sevenich, 2018).

\section{FUNCTIONAL CHANGE IN AGED MICROGLIA}

The change in microglial transcriptome with aging, microglial functions, such as phagocytosis, synaptic pruning, migration, and cytokine release to stimuli, can be also altered toward a decline or more dysregulation in the supportive and protective capacity. Microglia are remarkably versatile in their functions that overall achieve a homeostatic environment. Microglial dysfunction has been linked to neurodegenerative diseases. Live imaging of retinal microglia in young and aged mice revealed that aged microglia showed slower process motilities in homeostatic state and slower migrating response to laser-induced focal tissue damage (Damani et al., 2011). In addition, aged retinal microglia exhibited a sustained inflammatory response and defective phagocytosis (Damani et al., 2011). Aged microglia exhibited a heightened and prolonged response to inflammatory stimuli and showed a blunted response to IL-4, suggesting a reduced repair mechanism (Fenn et al., 2014). Furthermore, defective phagocytosis of myelin debris by aged microglia led to impaired remyelination (Rawji et al., 2020). Ex vivo cultured microglia isolated from the brain of aged mice constitutively secreted more amounts of pro-inflammatory cytokines, such as TNF- $\alpha$ and IL-6, and exhibited less $A \beta$ phagocytosis, leading to higher amyloid burden (Njie et al., 2012). Proteomic analysis of aged microglia isolated by CD11b magnetic beads showed that aged microglia exhibited disruption in chromatin remodeling, loss of nuclear architecture, and impairment in RNA processing (Flowers et al., 2017). In this study, aged microglia showed a bioenergetic shift from glucose to fatty acid utilization, linking with the study results that restoration of defective glycolytic metabolism could be a target for boosting the tolerant microglia induced by chronic amyloid $\beta$ exposure (Baik et al., 2019). A recent study demonstrated that aged microglia were not uniform throughout the brain but had transcriptomic diversity in a region-dependent manner, indicating differential susceptibility to aging factors (Grabert et al., 2016).

Considering that microglial phagocytic function contributes to clearance of aberrant proteins (amyloid $\beta$, Apolipoprotein $\mathrm{E}$, and $\alpha$-synuclein), and damaged neuronal debris, synaptic stripping, and remodeling for CNS homeostasis (Wake et al., 2013), decrease in phagocytic function with aging potentially have a direct link with increased susceptibility to the progression of neurodegenerative diseases. Signaling between CX3CL1 and its receptor CX3CR1 is critical for microglial synaptic pruning, phagocytosis, and migration in the adult brain; however, in the aged brain, their expression levels are decreased (Wynne et al., 2010; Deczkowska et al., 2018). In contrast, hallmarks of microglia activation such as major histocompatibility complex II (MHC II) and CD86, Toll-like receptors (TLRs), and nucleotide oligomerization domain (NOD)-like receptors (NLRs) are increased with age (Patterson, 2015). Age-dependent microglia dysfunction might be enhanced by the loss of endogenous TGF- $\beta 1$ to maintain mitochondria homeostasis. TGF- $\beta 1$ induces microglia phagocytosis of apoptotic cells via Mfge8 expression (Spittau et al., 2015).

Microglia priming is a stronger response than that of the stimulus-naïve microglia to a second inflammatory stimulus (Perry and Holmes, 2014). The exaggerated response to toxic stimuli, such as LPS, has been considered as a "primed state" of microglia with overproduction of pro-inflammatory cytokines or decreased anti-inflammatory factors. The "priming state" indicates a phenotypic shift of microglial cells toward a more sensitized state, responding to an additional stimulus more rapidly, longer, and to a greater degree than expected if non-primed (Harry, 2013). This exaggerated inflammatory response can compromise critical processes for optimal cognitive functioning. For example, IL-1 $\beta$ production in aged brain interrupted hippocampus-dependent memory systems and synaptic plasticity processes via disruption of brain-derived neurotrophic factor (BDNF) function (Norden and Godbout, 2013; Patterson, 2015). In addition, when aged mice received an intraperitoneal injection of LPS or Escherichia coli, IL-1 $\beta$ production was significantly higher and for a longer time than that in young mice (Godbout et al., 2005; Barrientos et al., 2009).

In summary, aged microglia are in a primed state and show an exaggerated response to inflammatory stimuli. In addition, aged microglia respond slowly to toxic stimuli, lose dynamic surveillance features, and exhibit reduced phagocytic function. These results were derived by live imaging using CX3CR1-specific GFP-tagged microglia; tissue staining using microglial markers, such as Iba-1 or CD11b, in aged mice; and acutely isolated microglia using CD11b magnetic beads or Percoll gradient. However, these methods cannot isolate perfectly pure resident microglia distinct from infiltrated monocyte/macrophage or CNS macrophages located in choroid plexus, meninges, and perivascular space, and we cannot determine the contaminated amount. In addition, an advanced dynamic contrast-enhanced magnetic resonance imaging protocol with high spatial and temporal resolutions quantified regional $\mathrm{BBB}$ permeability in the living human brain and found an age-dependent BBB breakdown in CA1 and dentate gyrus subdivisions of the hippocampus, supporting infiltration of macrophages and monocytes into CNS parenchyma (Montagne et al., 2015). Furthermore, we cannot discriminate whether higher inflammation to peripheral LPS injection is due to aged microglia or infiltrated macrophages/monocytes because peripheral LPS injection induces BBB disruption (Banks et al., 2015). Actually, highly pure microglia (CD $11 b^{\text {high }} \mathrm{CD} 45^{\text {int }}$ ) isolated from the human parietal cortex with the elimination of meningeal macrophages by fluorescence-activated cell sorting (FACS) indicated that microglia of physiologically aged mice do not recapitulate the effect of aging on human microglia, 

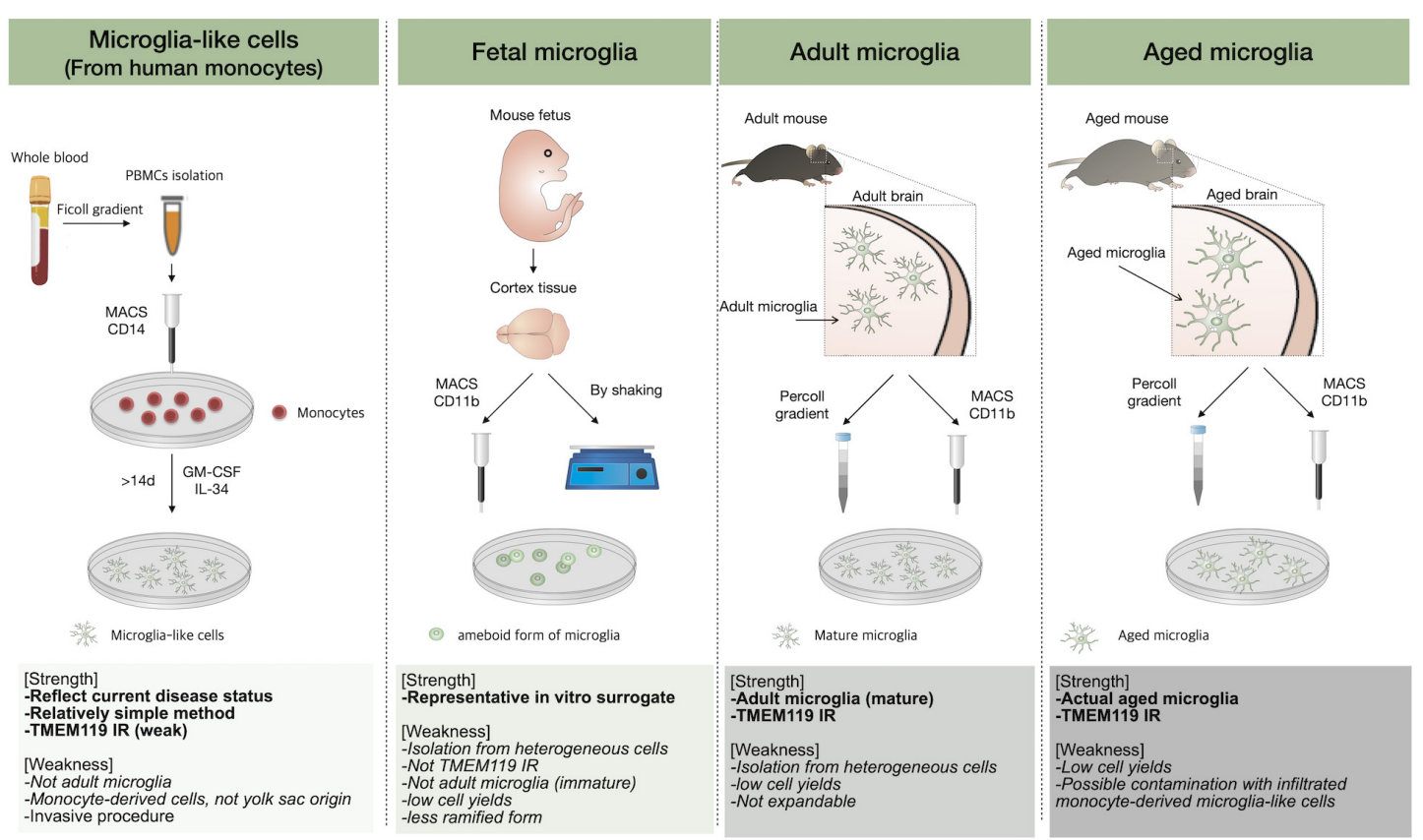

FIGURE 2 | In vitro microglial culture. The methods to obtain microglial cells are described and the strengths of each technique, followed by weaknesses, are listed.

and the top 100 differentially expressed genes in human aged microglia were more related with actin cytoskeleton-associated genes, sensome cell surface receptor, cell adhesion molecules, and surface receptors rather than inflammatory cytokines. These results suggest that decline in fine microglial processes, such as motility for surveillance, perturbed microglial migration, and reduced phagocytosis efficiency, may be associated with age-related neurodegeneration (Galatro et al., 2017). In a mouse model of telomere shortening $\left(\mathrm{mTerc}^{-/-}\right)$, it seems that peripheral LPS injection enhanced pro-inflammatory response in mTerc $\left(^{-/-}\right)$microglia, but the enhanced inflammatory response was not accompanied with genes related with aged microglia and correlated closely with infiltration of immune cells (Raj et al., 2015). Thus, the primed state of aged microglia might need to be reevaluated with purer isolated microglia with a stably expressed core marker during homeostasis and disease, especially according to neurodegenerative disease progression.

\section{In vitro Methods to Study Aged Microglia}

Microglia are widely involved in the homeostatic maintenance in the CNS, and age-associated microglial dysfunction is closely related to CNS diseases. Proper use of in vitro methods recapitulating adult microglia is required to study microglia; however, it has been difficult to recapitulate adult microglial cells perfectly due to the complexity of the origin and developmental process. In this section, we introduce the currently used in vitro methods for an accurate understanding of microglia. The features and limitations of each method are discussed, briefly referring to well-organized previous review papers (Timmerman et al., 2018; Angelova and Brown, 2019). A brief description of in vitro methods is illustrated in Figure 2. The description of "aged" microglia may indicate the inclusion of several distinct phenotypes and the term is uncertain (Koellhoffer et al., 2017). Based on the fact that senescent microglia or aged-like phenotype is not sufficient to cover aged microglia features, we have tried to use the terms as distinctly as possible. SASP as an alternative method to characterize aged microglia was indicated separately (Streit and Xue, 2014). Actually, aged microglia seem to have distinct features from in vitro senescent microglia although both aged microglia and senescent microglia show dysfunctional phenotypes such as impaired phagocytosis, slow migration, slow response to stimuli. Thus, in vitro senescent microglia might not recapitulate aged microglia perfectly so far.

\section{Microglial Cell Lines}

Initially, a cell line was suggested as a solution to the problem of not being able to secure enough microglial cells for detailed studies (Blasi et al., 1990; Nagai et al., 2001). The microglial cell line was established by immortalization. Such methods include viral transduction with oncogenes (e.g., v-raf, v-myc, v-mil), SV $40 \mathrm{~T}$ antigen, and cancerization (e.g., p53-deficient cell) using cells derived from various species, including mouse, rat, macaque, and human (Timmerman et al., 2018). Infinite growth capacity due to immortalization enables passage culture, and it is useful in research methods such as high-throughput screening assays that require a high number of cells, due to their relatively high growth rate (Dello Russo et al., 2018). However, immortalization is a double-edged sword. Immortalization has the advantage of being able to easily obtain a tremendous number of cells but rather distorts the properties of microglia due to artificial manipulation. Thus, they are different from adult microglia in genetic and functional aspects (Butovsky et al., 2014; Das et al., 


\section{Aged CNS}
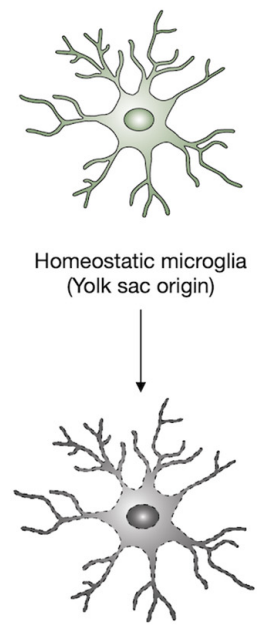

Loss of microglia
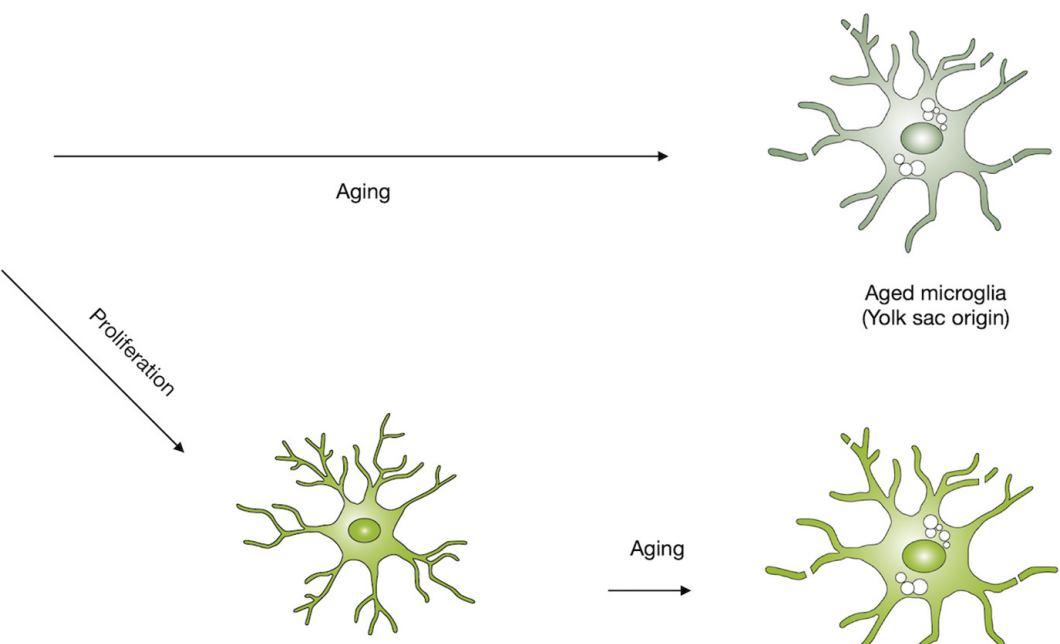

Repopulated microglia
Aged microglia (Yolk sac origin)
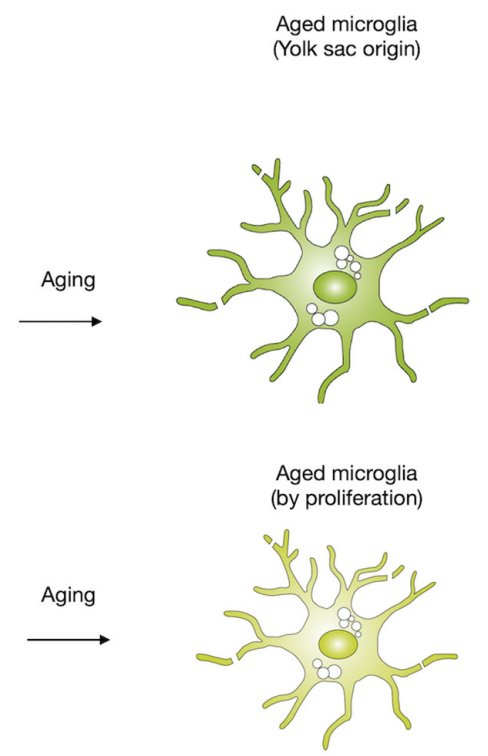

Aged microglia (Monocyte-derived)
Repopulated microglia

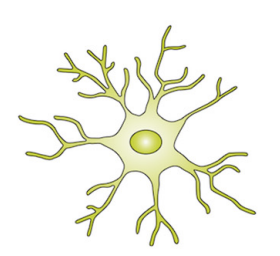

O) $0 \longdiv { 0 }$

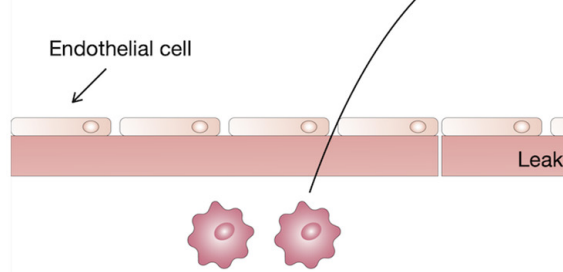

FIGURE 3 | Hypothesis on aged microglia heterogeneity. Based on the microglia origin and their limited repopulation, aged microglia might be composed of yolk-sac-originated microglia (homeostatic microglia), repopulated microglia from infiltrated monocytes, and proliferation of homeostatic microglia.

2016; Melief et al., 2016). Immortalized cells may also be not suitable for studying long-lived adult microglial cells, which show very low proliferative capacity at a healthy state (Fuger et al., 2017; Haenseler et al., 2017). For studying microglia senescence, there is a report that repeated LPS stimulation $(10 \mathrm{ng} / \mathrm{ml}$, every $48 \mathrm{~h})$ can induce cellular senescence in BV2 cells (Yu et al., 2012). In this study, BV2 senescence was evaluated by $\beta$-galactosidase staining, p53, and cell cycle arrest in G0/G1 phage, suggesting that multiple inflammatory stimuli may induce microglia senescence.

\section{Primary Fetal/Neonatal Microglial Culture}

Rodent primary microglia are commonly obtained from neonatal/fetal animals (Giulian and Baker, 1986), and human primary microglia also may be obtained from embryonic or fetal tissues (Satoh and Kim, 1994). After tissue collection, it is necessary to isolate a sufficient amount of only the desired microglial sample of high purity. There are several enzymatic and mechanical separation methods. In this process, one method is density gradient centrifugation; this method can isolate microglia with more than 99\% purity (Cardona et al., 2006a; ZuiderwijkSick et al., 2007). Other ways are magnetic-activated cell sorting (MACS) (Nikodemova and Watters, 2012; Mizee et al., 2017) and FACS (Olah et al., 2012; Bennett et al., 2016); these methods use microglia antibody coated with magnetic beads and fluorescent material, respectively, and the other is to perform the shaking procedure (Tamashiro et al., 2012).

Rodent primary microglia alone are insufficient to study human microglia due to interspecies differences with regard to features of adhesion, proliferation rates, and expression of key receptors (Smith and Dragunow, 2014). Because no 
artificial treatment, such as genetic modification, is applied, fetal/neonatal microglia culture has the advantage that it is similar to resident microglia compared with cell lines, but passage culture is difficult, and too many animals are required to obtain a high number of cells. Notably, early fetal or neonatal microglia differ in many ways, including transcriptome, function, morphology, and physiology, from adult microglia settled in the adult brain after BBB formation (Butovsky et al., 2014; Matcovitch-Natan et al., 2016; Prinz et al., 2019). For induction of senescent microglia, long-term culture using fetal microglia was proposed (Caldeira et al., 2014). In this study, 16 days in vitro (16 DIV) cultured microglia showed slightly increased ramified morphology compared with the ameboid form of $2 \mathrm{DIV}$ and showed reduced migration and phagocytosis compared with 2 DIV. In addition, 16 DIV exhibited enhanced $\beta$-galactosidase staining and decreased autophagy, indicating that this method induces senescence in microglia. HIV-1 also induces a senescence-like phenotype in human microglia (Chen et al., 2018). Primary human fetal microglia exposed to singleround infectious HIV-1 pseudotypes had significantly elevated senescence-associated $\beta$-galactosidase activity, p21 levels, and production of cytokines (such as IL-6 and IL-8), which are potentially indicative of a SASP, and showed mitochondrial dysfunction. Another method to induce $\beta$-galactosidase activity in microglia is dexamethasone (DEX) treatment (Park et al., 2019). In this method, we found that DEX induced ramified form but showed dysfunctional phagocytosis and tolerant response (decreased mRNA of pro- and anti-inflammatory cytokines) with downregulated homeostatic genes, such as Cx3cr1, Cd200r, P2ry12, and Trem2. They were partially unlike aged microglia because DEX-treated microglia showed increased autophagy and decreased inflammatory cytokines. Based on the fact that dystrophic microglia can be identified by high ferritin, iron content also can generate a microglia model of an aged-like phenotype (Brown, 2009).

\section{Direct Isolation of Adult Microglia and ex vivo Microglial Culture}

As the need for adult microglia has emerged, many studies have directly isolated microglia from adult animals. This is performed in a similar way to primary fetal/neonatal microglia culture, with the difference that adult microglia can be obtained after mechanical and enzymatic dissociation of the rodent brain. Generally, after digestion, adult microglia are separated from the cocktail containing collagenase and dispase using a discontinuous Percoll gradient or MACS or FACS (Becher and Antel, 1996; Cardona et al., 2006a; Nikodemova and Watters, 2012; Olah et al., 2012; Bennett et al., 2016; Mizee et al., 2017). Microglia obtained in this way can be used for (single-cell) transcriptome analysis, high-density microarray, proteomic, or cytometric analysis. The main advantage of this method is the ability to obtain adult microglia with specific features as mentioned above. Namely, it can reflect the state of microglia present in the adult brain environment, although acutely isolated adult microglia rapidly lost TMEM119 expression in culture media (Bohlen et al., 2017). Although it has limitations like inefficient passage culture and low cell yield leading to a high number of animals being used (Timmerman et al., 2018), it is undeniably the most reliable way to obtain actual aged microglia from aged rodents or humans. Notably, the actual feature of aged microglia was confirmed by these methods (Galatro et al., 2017; Olah et al., 2018; Ximerakis et al., 2019). However, direct isolation from aged animals for experiments requires high effort and can be timeconsuming. Alternatively, Ercc1 mutant mice, a DNA repairdeficient mouse that exhibits characteristics of accelerated aging in CNS and other tissues, might be used for studying aged microglia without long aging periods, but this may not reflect natural aging due to genetic manipulation (Raj et al., 2014). Acutely isolated murine microglia from aged mice show different features from senescent microglia obtained by long-term fetal microglia. Senescent microglia exhibited shortened telomeres with increased telomerase activity, whereas aged microglia showed unaltered telomeres and reduced telomerase activity (Stojiljkovic et al., 2019). In this study, senescent microglia showed increased p16, p21, and p53 expression, while aged microglia only exhibited p16 elevation, suggesting that aged microglia show dysfunctional features but cannot exhibit key senescence markers.

\section{Microglia-Like Cells From Human Induced Pluripotent Stem Cells (iPSCs)}

Extracting living brain cells containing microglia directly from the animal or human brain presents technical and/or ethical problems. To overcome these issues, in vitro models mentioned below have been proposed. iPSCs or monocytederived microglia-like cells were established along with new adult microglial markers.

Induced pluripotent stem cells are reprogrammed adult cells, such as fibroblasts, generated by introducing four transcription factors (Oct3/4, Sox2, c-Myc, and Klf4) (Takahashi and Yamanaka, 2006). The existing in vitro microglia models, such as primary cultures, present difficulty in obtaining sufficient normal and disease-associated microglial cell sources. In addition, microglia are very sensitive to the environment in their identity, so they quickly lose their characteristics when separated from the brain microenvironment (Butovsky et al., 2014; Bohlen et al., 2017). To resolve these limitations and reflect microglial development in the in vitro model as much as possible, many studies have been conducted on the protocols for in vitro differentiation of iPSCs into microglia-like cells.

For the first time, a robust protocol for differentiating human iPSCs and embryonic stem cells (ESCs) into microglia-like cells using the embryonic body (EB) was suggested (Muffat et al., 2016). The microglia-like cells were cultured in serum-free conditioned media to reflect the development environment of actual microglia. These microglia-like cells show characteristics of human primary fetal and adult microglia in gene expression, signature marker, and microglial function (e.g., phagocytosis). In addition, they particularly expressed the markers P2RY12 and TMEM119 and progressively showed a ramified form. Unlike most other iPSC-derived microglia protocol results, this approach showed that iPSC-derived microglia-like cells 
have features of adult microglia as well as human primary fetal microglia.

Another protocol differentiated iPSCs into human microglialike cells through exposure to defined factors following the astrocyte co-culture protocol, which includes factors involved in proliferation, such as IL-3, M-CSF, and granulocytemacrophage-CSF (GM-CSF), in the medium (Pandya et al., 2017). Before final differentiation into microglia-like cells, first, an intermediate process of differentiation into hematopoietic progenitor-like cells (iPSC-HPC) is performed. This makes it possible to analogously reflect the ontogeny procedure of microglia. iPSC-HPC has marked expression of CD34 and CD43, markers of hematopoietic cells. Subsequently, as the differentiation into human microglia-like cells progresses, more microglia-related markers, such as CD11b, Iba-1, HLA-KR, TREM2, and CX3CR1, were expressed.

In a similar vein to the study of Muffat et al. (2016), Abud et al. (2017) published a fully defined serum-free protocol that ensures high purity $(>97 \%)$ and large quantities. Initially, CD $43^{+}$iPSCs differentiate into myeloid progenitors by exposure to defined medium and transient low oxygen levels (5\%). After 10 days, the medium is replaced with serum-free media containing M-CSF, IL-34, TGF- $\beta 1$, and insulin. Thereafter, microglia-like cells are exposed to CD200 and CX3CL1 and continue to mature, showing more ramified forms as they mature. Gene expression analysis and functional assessment demonstrated that these microglia-like cells highly resemble human fetal and adult primary microglia. Furthermore, Abud et al. (2017) demonstrated the effect of coculture with other neural cells on morphology and function as well as gene expression in microglia.

Based on microglial origin, Douvaras et al. (2017) described a reproducible protocol that uses PSC-derived myeloid progenitors, which are considered to correspond to in vivo primitive yolk-sac myeloid progenitors in chemically defined conditions. PSCs, including ESCs and iPSCs, are stimulated with a myeloid inductive medium and treated with microgliapromoting cytokines. As a result, $\mathrm{KDR}^{+} \mathrm{CD}^{235 \mathrm{a}^{+}}$primitive hemangioblasts are generated, which then change to $\mathrm{CD} 45^{+}$ $\mathrm{CX} 3 \mathrm{CR} 1^{+}$microglial progenitors in vitro. Subsequently, the addition of IL-34 and GM-CSF to plated microglial progenitors differentiates into iPSC-derived microglia-like cells (Ohgidani et al., 2014), ramifying with highly motile processes and monitoring the microenvironment like in vivo microglia (Davalos et al., 2005). iPSC-derived microglia-like cells express not only typical microglial markers, such as IBA1, CD11c, TMEM119, P2RY12, CD11b, and CX3CR1, but also signature genes in human primary microglia, such as C1QA, GAS6, GPR34, MERTK, P2RY12, and PROS1 (Butovsky et al., 2014). Furthermore, they showed phagocytosis and intracellular $\mathrm{Ca}_{2}{ }^{+}$ transient in response to ADP.

To recapitulate the ontogeny of microglia, Haenseler et al. (2017) established a very efficient human iPSC-derived microglia model analogous to the microglial ontogenetic development process. Microglia originate from yolk-sac-derived macrophages, which have MYB-independent and PU.1- and Irf8-dependent properties (Schulz et al., 2012; Kierdorf et al., 2013). To consider this fact, embryonic MYB-independent iPSC-derived macrophages, which were harvested from EB cultured with BMP4, VEGF, SCF, IL-3, and M-CSF, were co-cultured with iPSC-derived cortical neurons for 2 weeks. The obtained iPSCderived microglia-like cells express major microglia-specific markers, form highly dynamic ramified morphology, and perform phagocytosis. In addition, transcriptome analysis results are similar to those of human fetal primary microglia. In particular, the resulting co-cultures upregulate homeostasisrelated function pathways, downregulate pathogen response pathways, and promote enhanced anti-inflammatory response compared with corresponding monocultures. This protocol avoids repetitive cell sorting or replating, resulting in relative simplicity, high efficiency, and yield.

Above mentioned iPSC-derived microglia-like cells have the advantage of securing a sufficient cell source. Another advantage is that iPSC-derived cells of normal donors can be compared with those from patients with neurological disorders, and the genetic background of the patient can be considered. However, despite these advantages, research using iPSC-derived microglialike cells has limitations to overcome. First, there are too many models with different protocols. To describe the most reliable approaches, comparison and integration between each approach are necessary (Timmerman et al., 2018). In addition, most microglia in vitro models using iPSC are inefficient due to low yields, over-time, and cost ( $\mathrm{Li}$ and Barres, 2018). The effects of the CNS microenvironment cannot be reflected, and most of the iPSC-derived microglia-like cells studied so far have characteristics of primary microglia and not adult microglia. Therefore, developing methods for differentiating microglialike cells similar to adult microglia may be better suited for neurodegenerative disease studies. Above all, because iPSC technology accompanies cell rejuvenation, iPSC cannot reflect the aging feature of the origin cells obtained from aged humans (Mertens et al., 2015). To our best knowledge, there is no report on in vitro aging method utilizing microglia-like cells derived from iPSCs yet.

\section{Monocyte-Derived Microglia-Like Cells}

There are other methods to obtain microglia-like cells by using monocytes. iPSCs-derived microglia-like cells have limitations that they do not reflect the current physiological and pathological status due to rejuvenation (Mertens et al., 2015), but monocytederived microglia-like cells have the advantages that they mirror the state of the donor (Ohgidani et al., 2015; Ryan et al., 2017; Sellgren et al., 2017). Thus, induced microglia-like cells from monocytes of aged humans may reflect aged microglia. However, this needs to be validated.

Previously, it has been proven that rat monocytes or macrophages cultured in an astrocyte-conditioned medium (ACM) develop into microglia-like cells showing characteristics of microglia, including ramified morphology (Kettenmann and Ilschner, 1993; Schmidtmayer et al., 1994). Based on this, Leone et al. (2006) showed that human monocytes cultured in ACM exhibit microglia-like features in many respects. Later, it was found that GM-CSF and IL-34, cytokines secreted by astrocytes (Guillemin et al., 1996; Noto et al., 2014), are at least essential in inducing microglia-like cells from human peripheral blood 
cells (Ohgidani et al., 2014). In particular, IL-34 was found to be a major factor in the proliferation of microglia (GomezNicola et al., 2013). Within 2 weeks, using a cocktail of GM-CSF and IL-34 successfully induced microglia-like cells from human monocytes. These cells represented the various characteristics of microglia, including ramified morphology; markers, such as high CD11 and CX3CR1 and low CD45 and CCR2; phagocytosis; and releasing cytokines related to inflammation (Ohgidani et al., 2014). In the following studies, these induced microglia-like cells were demonstrated to enable various approaches to study microglia in psychiatric disorders by translational research. This can be linked with drug efficacy screening and personalized medicine to maximize the therapeutic effect (Ohgidani et al., 2015). Gene expression analysis showed that microglia-specific genes involved in microglial function are also expressed in monocyte-derived microglia (Ryan et al., 2017). Representative microglial genes TGFBR1 and C1QB are important mediators for synaptic pruning (Bialas and Stevens, 2013), PROS1 is involved in phagocytosis (Fourgeaud et al., 2016), and P2RX7 induces activation and proliferation of microglia (Monif et al., 2009). In addition, monocyte-derived microglia-like cells have also been applied to translational research (Ohgidani et al., 2015; Ryan et al., 2017; Sellgren et al., 2017).

However, as the progenitor of microglia is early erythroid myeloid progenitors (eEMP) originating from hematopoietic stem cells, there is a fundamental limitation that monocytederived microglia-like cells and microglia differ in their origins. Moreover, obtaining enough microglia-like cells from human blood monocytes requires repeated invasive procedures (Beutner et al., 2013).

Taken together, each method for culturing microglia in vitro has advantages and disadvantages. Although monocyte-derived microglia-like cells can better recapitulate aging as they are not rejuvenated during reprogramming as are iPSCs-derived microglia-like cells, it has not been confirmed whether monocytes obtained from aged humans can actually differentiate to microglia-like cells from aged humans and reflect their features. In the case of rodent microglia, several methods for inducing senescence have been proposed as mentioned above, but the in vitro methods require a significant amount of primary microglial cells. To address this issue, our laboratory developed a system to obtain bankable and expandable adult-like microglia (NEL-MG) by using the head neuroepithelial layer in the mouse embryo (You et al., 2021).

\section{REFERENCES}

Abud, E. M., Ramirez, R. N., Martinez, E. S., Healy, L. M., Nguyen, C. H. H., Newman, S. A., et al. (2017). iPSC-derived human microglia-like cells to study neurological diseases. Neuron 94, 278-293 e279. doi: 10.1016/j.neuron.2017. 03.042

Ajami, B., Bennett, J. L., Krieger, C., Tetzlaff, W., and Rossi, F. M. (2007). Local self-renewal can sustain CNS microglia maintenance and function throughout adult life. Nat. Neurosci. 10, 1538-1543. doi: 10.1038/nn2014

Angelova, D. M., and Brown, D. R. (2019). Microglia and the aging brain: are senescent microglia the key to neurodegeneration? J. Neurochem. 151, 676-688. doi: $10.1111 /$ jnc. 14860

\section{CONCLUSION}

Microglia are yolk-sac-derived CNS cells with distinct origins different from neurons, astrocytes, and oligodendrocytes. They are long-lived cells, and when they die by aging and other causes, they might be replaced by their proliferation or peripheral immune cells rather than being regenerated by their progenitors like other CNS cells, suggesting aged microglia heterogeneity (Figure 3). The function of microglia is also very extensive, affecting our brain homeostasis throughout life, from neurodevelopment to neurodegenerative changes. Due to the transcriptomic dissimilarity of the repopulating microglia and limited repopulating capacity, keeping the original resident microglia healthy for a long time seems to be another strategy to prevent neurodegenerative diseases. Moreover, with the evolving understanding of microglia, to understand the aging process of microglia, using further improved aged microglia models may provide us with a crucial key to find alternative therapeutic strategies for neurodegenerative diseases.

\section{AUTHOR CONTRIBUTIONS}

H-JY and M-SK wrote the manuscript. M-SK supervised all the processes, determined the direction of the manuscript, and approved the final submission of the manuscript. Both authors critically revised the manuscript and confirmed the author's contribution statement.

\section{FUNDING}

This research was supported by the National Research Foundation of Korea (NRF) grant funded by the Korean Government (MIST) (2019M3C7A1032561 and 2021M3E5D9025027).

\section{ACKNOWLEDGMENTS}

We appreciate Dahye Kim and Chan Rim (graduate student) for providing nice illustrations describing our perspectives.

Badimon, A., Strasburger, H. J., Ayata, P., Chen, X., Nair, A., Ikegami, A., et al. (2020). Negative feedback control of neuronal activity by microglia. Nature 586 , 417-423. doi: 10.1038/s41586-020-2777-8

Baik, S. H., Kang, S., Lee, W., Choi, H., Chung, S., Kim, J. I., et al. (2019). A breakdown in metabolic reprogramming causes microglia dysfunction in Alzheimer's disease. Cell Metab. 30, 493-507 e496. doi: 10.1016/j.cmet.2019.06. 005

Banks, W. A., Gray, A. M., Erickson, M. A., Salameh, T. S., Damodarasamy, M., Sheibani, N., et al. (2015). Lipopolysaccharide-induced blood-brain barrier disruption: roles of cyclooxygenase, oxidative stress, neuroinflammation, and elements of the neurovascular unit. J. Neuroinflammation 12:223. doi: 10.1186/ s12974-015-0434-1 
Barrientos, R. M., Frank, M. G., Hein, A. M., Higgins, E. A., Watkins, L. R., Rudy, J. W., et al. (2009). Time course of hippocampal IL-1 beta and memory consolidation impairments in aging rats following peripheral infection. Brain Behav. Immun. 23, 46-54. doi: 10.1016/j.bbi.2008.07.002

Becher, B., and Antel, J. P. (1996). Comparison of phenotypic and functional properties of immediately ex vivo and cultured human adult microglia. Glia 18, 1-10. doi: 10.1002/(SICI)1098-1136(199609)18:1<1::AID-GLIA1>3.0.CO;2-6

Bennett, M. L., Bennett, F. C., Liddelow, S. A., Ajami, B., Zamanian, J. L., Fernhoff, N. B., et al. (2016). New tools for studying microglia in the mouse and human CNS. Proc. Natl. Acad. Sci. U.S.A. 113, E1738-E1746. doi: 10.1073/pnas. 1525528113

Beutner, C., Linnartz-Gerlach, B., Schmidt, S. V., Beyer, M., Mallmann, M. R., Staratschek-Jox, A., et al. (2013). Unique transcriptome signature of mouse microglia. Glia 61, 1429-1442. doi: 10.1002/glia.22524

Bialas, A. R., and Stevens, B. (2013). TGF-beta signaling regulates neuronal C1q expression and developmental synaptic refinement. Nat. Neurosci. 16, 17731782. doi: $10.1038 / \mathrm{nn} .3560$

Bisht, K., Sharma, K. P., Lecours, C., Sanchez, M. G., El Hajj, H., Milior, G., et al. (2016). Dark microglia: a new phenotype predominantly associated with pathological states. Glia 64, 826-839. doi: 10.1002/glia.22966

Blasi, E., Barluzzi, R., Bocchini, V., Mazzolla, R., and Bistoni, F. (1990). Immortalization of murine microglial cells by a v-raf/v-myc carrying retrovirus. J. Neuroimmunol. 27, 229-237. doi: 10.1016/0165-5728(90)90073-v

Bohlen, C. J., Bennett, F. C., Tucker, A. F., Collins, H. Y., Mulinyawe, S. B., and Barres, B. A. (2017). Diverse requirements for microglial survival, specification, and function revealed by defined-medium cultures. Neuron 94, 759-773 e758. doi: 10.1016/j.neuron.2017.04.043

Brionne, T. C., Tesseur, I., Masliah, E., and Wyss-Coray, T. (2003). Loss of TGFbeta 1 leads to increased neuronal cell death and microgliosis in mouse brain. Neuron 40, 1133-1145. doi: 10.1016/s0896-6273(03)00766-9

Brown, D. R. (2009). Role of microglia in age-related changes to the nervous system. Sci. World J. 9, 1061-1071. doi: 10.1100/tsw.2009.111

Butovsky, O., Jedrychowski, M. P., Cialic, R., Krasemann, S., Murugaiyan, G., Fanek, Z., et al. (2015). Targeting miR-155 restores abnormal microglia and attenuates disease in SOD1 mice. Ann. Neurol. 77, 75-99.

Butovsky, O., Jedrychowski, M. P., Moore, C. S., Cialic, R., Lanser, A. J., Gabriely, G., et al. (2014). Identification of a unique TGF-beta-dependent molecular and functional signature in microglia. Nat. Neurosci. 17, 131-143. doi: 10.1038/nn. 3599

Butovsky, O., and Weiner, H. L. (2018). Microglial signatures and their role in health and disease. Nat. Rev. Neurosci. 19, 622-635. doi: 10.1038/s41583-0180057-5

Buttgereit, A., Lelios, I., Yu, X., Vrohlings, M., Krakoski, N. R., Gautier, E. L., et al. (2016). Sall1 is a transcriptional regulator defining microglia identity and function. Nat. Immunol. 17, 1397-1406.

Caldeira, C., Oliveira, A. F., Cunha, C., Vaz, A. R., Falcao, A. S., Fernandes, A., et al. (2014). Microglia change from a reactive to an age-like phenotype with the time in culture. Front. Cell Neurosci. 8:152. doi: 10.3389/fncel.2014.00152

Cardona, A. E., Huang, D., Sasse, M. E., and Ransohoff, R. M. (2006a). Isolation of murine microglial cells for RNA analysis or flow cytometry. Nat. Protoc. 1, 1947-1951. doi: 10.1038/nprot.2006.327

Cardona, A. E., Pioro, E. P., Sasse, M. E., Kostenko, V., Cardona, S. M., Dijkstra, I. M., et al. (2006b). Control of microglial neurotoxicity by the fractalkine receptor. Nat. Neurosci. 9, 917-924. doi: 10.1038/nn1715

Chen, N. C., Partridge, A. T., Tuzer, F., Cohen, J., Nacarelli, T., Navas-Martin, S., et al. (2018). Induction of a senescence-like phenotype in cultured human fetal microglia during HIV-1 infection. J. Gerontol. A Biol. Sci. Med. Sci. 73, 1187-1196. doi: 10.1093/gerona/gly022

Chen, S., Luo, D., Streit, W. J., and Harrison, J. K. (2002). TGF-betal upregulates CX3CR1 expression and inhibits fractalkine-stimulated signaling in rat microglia. J. Neuroimmunol. 133, 46-55. doi: 10.1016/s0165-5728(02)00354-5

Cheray, M., and Joseph, B. (2018). Epigenetics control microglia plasticity. Front. Cell Neurosci. 12:243. doi: 10.3389/fncel.2018.00243

Chitu, V., Gokhan, S., Nandi, S., Mehler, M. F., and Stanley, E. R. (2016). Emerging roles for CSF-1 receptor and its ligands in the nervous system. Trends Neurosci. 39, 378-393. doi: 10.1016/j.tins.2016.03.005

Cronk, J. C., Derecki, N. C., Ji, E., Xu, Y., Lampano, A. E., Smirnov, I., et al. (2015). Methyl-CpG binding protein 2 regulates microglia and macrophage gene expression in response to inflammatory stimuli. Immunity 42, 679-691. doi: 10.1016/j.immuni.2015.03.013

Cronk, J. C., Filiano, A. J., Louveau, A., Marin, I., Marsh, R., Ji, E., et al. (2018). Peripherally derived macrophages can engraft the brain independent of irradiation and maintain an identity distinct from microglia. J. Exp. Med. 215, 1627-1647. doi: 10.1084/jem.20180247

Damani, M. R., Zhao, L., Fontainhas, A. M., Amaral, J., Fariss, R. N., and Wong, W. T. (2011). Age-related alterations in the dynamic behavior of microglia. Aging Cell 10, 263-276. doi: 10.1111/j.1474-9726.2010.00660.x

Damisah, E. C., Hill, R. A., Rai, A., Chen, F., Rothlin, C. V., Ghosh, S., et al. (2020). Astrocytes and microglia play orchestrated roles and respect phagocytic territories during neuronal corpse removal in vivo. Sci. Adv. 6:eaba3239. doi: 10.1126/sciadv.aba3239

Das, A., Kim, S. H., Arifuzzaman, S., Yoon, T., Chai, J. C., Lee, Y. S., et al. (2016). Transcriptome sequencing reveals that LPS-triggered transcriptional responses in established microglia BV2 cell lines are poorly representative of primary microglia. J. Neuroinflammation 13:182. doi: 10.1186/s12974-016-0644-1

Davalos, D., Grutzendler, J., Yang, G., Kim, J. V., Zuo, Y., Jung, S., et al. (2005). ATP mediates rapid microglial response to local brain injury in vivo. Nat. Neurosci. 8, 752-758. doi: 10.1038/nn1472

Deczkowska, A., Amit, I., and Schwartz, M. (2018). Microglial immune checkpoint mechanisms. Nat. Neurosci. 21, 779-786.

Dello Russo, C., Cappoli, N., Coletta, I., Mezzogori, D., Paciello, F., Pozzoli, G., et al. (2018). The human microglial HMC3 cell line: where do we stand? A systematic literature review. J. Neuroinflammation 15:259. doi: 10.1186/s12974-0181288-0

Douvaras, P., Sun, B., Wang, M., Kruglikov, I., Lallos, G., Zimmer, M., et al. (2017). Directed differentiation of human pluripotent stem cells to microglia. Stem Cell Rep. 8, 1516-1524. doi: 10.1016/j.stemcr.2017.04.023

Elmore, M. R., Najafi, A. R., Koike, M. A., Dagher, N. N., Spangenberg, E. E., Rice, R. A., et al. (2014). Colony-stimulating factor 1 receptor signaling is necessary for microglia viability, unmasking a microglia progenitor cell in the adult brain. Neuron 82, 380-397. doi: 10.1016/j.neuron.2014.02.040

Fenn, A. M., Hall, J. C., Gensel, J. C., Popovich, P. G., and Godbout, J. P. (2014). IL-4 signaling drives a unique arginase+/IL-1beta+ microglia phenotype and recruits macrophages to the inflammatory CNS: consequences of age-related deficits in IL-4Ralpha after traumatic spinal cord injury. J. Neurosci. 34, 8904-8917. doi: 10.1523/JNEUROSCI.1146-14.2014

Flowers, A., Bell-Temin, H., Jalloh, A., Stevens, S. M. Jr., and Bickford, P. C. (2017). Proteomic anaysis of aged microglia: shifts in transcription, bioenergetics, and nutrient response. J. Neuroinflammation 14:96. doi: 10.1186/s12974-0170840-7

Ford, A. L., Goodsall, A. L., Hickey, W. F., and Sedgwick, J. D. (1995). Normal adult ramified microglia separated from other central nervous system macrophages by flow cytometric sorting. Phenotypic differences defined and direct ex vivo antigen presentation to myelin basic protein-reactive CD4+ T cells compared. J. Immunol. 154, 4309-4321.

Fourgeaud, L., Traves, P. G., Tufail, Y., Leal-Bailey, H., Lew, E. D., Burrola, P. G., et al. (2016). TAM receptors regulate multiple features of microglial physiology. Nature 532, 240-244. doi: 10.1038/nature17630

Fuger, P., Hefendehl, J. K., Veeraraghavalu, K., Wendeln, A. C., Schlosser, C., Obermuller, U., et al. (2017). Microglia turnover with aging and in an Alzheimer's model via long-term in vivo single-cell imaging. Nat. Neurosci. 20, 1371-1376. doi: 10.1038/nn.4631

Galatro, T. F., Holtman, I. R., Lerario, A. M., Vainchtein, I. D., Brouwer, N., Sola, P. R., et al. (2017). Transcriptomic analysis of purified human cortical microglia reveals age-associated changes. Nat. Neurosci. 20, 1162-1171. doi: $10.1038 / \mathrm{nn} .4597$

Galloway, D. A., Phillips, A. E. M., Owen, D. R. J., and Moore, C. S. (2019). Phagocytosis in the brain: homeostasis and disease. Front. Immunol. 10:790. doi: 10.3389/fimmu.2019.00790

Ginhoux, F., Greter, M., Leboeuf, M., Nandi, S., See, P., Gokhan, S., et al. (2010). Fate mapping analysis reveals that adult microglia derive from primitive macrophages. Science 330, 841-845. doi: 10.1126/science.119 4637

Giulian, D., and Baker, T. J. (1986). Characterization of ameboid microglia isolated from developing mammalian brain. J. Neurosci. 6, 2163-2178. doi: 10.1523/ JNEUROSCI.06-08-02163.1986 
Godbout, J. P., Chen, J., Abraham, J., Richwine, A. F., Berg, B. M., Kelley, K. W., et al. (2005). Exaggerated neuroinflammation and sickness behavior in aged mice following activation of the peripheral innate immune system. FASEB J. 19, 1329-1331. doi: 10.1096/fj.05-3776fje

Goldmann, T., Wieghofer, P., Muller, P. F., Wolf, Y., Varol, D., Yona, S., et al. (2013). A new type of microglia gene targeting shows TAK1 to be pivotal in CNS autoimmune inflammation. Nat. Neurosci. 16, 1618-1626. doi: 10.1038/ nn.3531

Gomez-Nicola, D., Fransen, N. L., Suzzi, S., and Perry, V. H. (2013). Regulation of microglial proliferation during chronic neurodegeneration. J. Neurosci. 33, 2481-2493. doi: 10.1523/JNEUROSCI.4440-12.2013

Grabert, K., Michoel, T., Karavolos, M. H., Clohisey, S., Baillie, J. K., Stevens, M. P., et al. (2016). Microglial brain region-dependent diversity and selective regional sensitivities to aging. Nat. Neurosci. 19, 504-516. doi: 10.1038/nn. 4222

Graeber, M. B., and Streit, W. J. (2010). Microglia: biology and pathology. Acta Neuropathol. 119, 89-105. doi: 10.1007/s00401-009-0622-0

Guillemin, G., Boussin, F. D., Le Grand, R., Croitoru, J., Coffigny, H., and Dormont, D. (1996). Granulocyte macrophage colony stimulating factor stimulates in vitro proliferation of astrocytes derived from simian mature brains. Glia 16, 71-80. doi: 10.1002/(SICI)1098-1136(199601)16:1<71::AID-GLIA8>3. $0 . \mathrm{CO} ; 2-\mathrm{E}$

Guneykaya, D., Ivanov, A., Hernandez, D. P., Haage, V., Wojtas, B., Meyer, N., et al. (2018). Transcriptional and translational differences of microglia from male and female brains. Cell Rep. 24, 2773-2783 e2776. doi: 10.1016/j.celrep. 2018.08.001

Haenseler, W., Sansom, S. N., Buchrieser, J., Newey, S. E., Moore, C. S., Nicholls, F. J., et al. (2017). A Highly efficient human pluripotent stem cell microglia model displays a neuronal-co-culture-specific expression profile and inflammatory response. Stem Cell Rep. 8, 1727-1742. doi: 10.1016/j.stemcr. 2017.05.017

Harrison, J. K., Jiang, Y., Chen, S., Xia, Y., Maciejewski, D., Mcnamara, R. K., et al. (1998). Role for neuronally derived fractalkine in mediating interactions between neurons and CX3CR1-expressing microglia. Proc. Natl. Acad. Sci. U.S.A. 95, 10896-10901. doi: 10.1073/pnas.95.18.10896

Harry, G. J. (2013). Microglia during development and aging. Pharmacol. Ther. $139,313-326$.

Herrera-Molina, R., and von Bernhardi, R. (2005). Transforming growth factorbeta 1 produced by hippocampal cells modulates microglial reactivity in culture. Neurobiol. Dis. 19, 229-236. doi: 10.1016/j.nbd.2005.01.003

Huang, Y., Xu, Z., Xiong, S., Sun, F., Qin, G., Hu, G., et al. (2018). Repopulated microglia are solely derived from the proliferation of residual microglia after acute depletion. Nat. Neurosci. 21, 530-540.

Karlen, S. J., Miller, E. B., Wang, X., Levine, E. S., Zawadzki, R. J., and Burns, M. E. (2018). Monocyte infiltration rather than microglia proliferation dominates the early immune response to rapid photoreceptor degeneration. J. Neuroinflammation 15:344. doi: 10.1186/s12974-018-1365-4

Kettenmann, H., Hanisch, U. K., Noda, M., and Verkhratsky, A. (2011). Physiology of microglia. Physiol. Rev. 91, 461-553.

Kettenmann, H., and Ilschner, S. (1993). Physiological properties of microglia. Clin. Neuropathol. 12, 306-307.

Kierdorf, K., Erny, D., Goldmann, T., Sander, V., Schulz, C., Perdiguero, E. G., et al. (2013). Microglia emerge from erythromyeloid precursors via Pu.1and Irf8-dependent pathways. Nat. Neurosci. 16, 273-280. doi: 10.1038/nn. 3318

Koellhoffer, E. C., Mccullough, L. D., and Ritzel, R. M. (2017). Old maids: aging and its impact on microglia function. Int. J. Mol. Sci. 18, 769. doi: 10.3390/ ijms 18040769

Kreisel, T., Frank, M. G., Licht, T., Reshef, R., Ben-Menachem-Zidon, O., Baratta, M. V., et al. (2014). Dynamic microglial alterations underlie stress-induced depressive-like behavior and suppressed neurogenesis. Mol. Psychiatry 19, 699709. doi: $10.1038 / \mathrm{mp} .2013 .155$

Lassmann, H., Schmied, M., Vass, K., and Hickey, W. F. (1993). Bone marrow derived elements and resident microglia in brain inflammation. Glia 7, 19-24. doi: 10.1002/glia.440070106

Leone, C., Le Pavec, G., Meme, W., Porcheray, F., Samah, B., Dormont, D., et al. (2006). Characterization of human monocyte-derived microglia-like cells. Glia 54, 183-192. doi: 10.1002/glia.20372
Li, Q., and Barres, B. A. (2018). Microglia and macrophages in brain homeostasis and disease. Nat. Rev. Immunol. 18, 225-242. doi: 10.1038/nri.2017.125

Lloyd, A. F., Davies, C. L., and Miron, V. E. (2017). Microglia: origins, homeostasis, and roles in myelin repair. Curr. Opin. Neurobiol. 47, 113-120. doi: 10.1016/j. conb.2017.10.001

Matcovitch-Natan, O., Winter, D. R., Giladi, A., Vargas Aguilar, S., Spinrad, A., Sarrazin, S., et al. (2016). Microglia development follows a stepwise program to regulate brain homeostasis. Science 353:aad8670. doi: 10.1126/science.aad8670

Matt, S. M., Lawson, M. A., and Johnson, R. W. (2016). Aging and peripheral lipopolysaccharide can modulate epigenetic regulators and decrease IL-1beta promoter DNA methylation in microglia. Neurobiol. Aging 47, 1-9. doi: 10. 1016/j.neurobiolaging.2016.07.006

Melief, J., Koning, N., Schuurman, K. G., Van De Garde, M. D., Smolders, J., Hoek, R. M., et al. (2012). Phenotyping primary human microglia: tight regulation of LPS responsiveness. Glia 60, 1506-1517. doi: 10.1002/glia.22370

Melief, J., Sneeboer, M. A., Litjens, M., Ormel, P. R., Palmen, S. J., Huitinga, I., et al. (2016). Characterizing primary human microglia: a comparative study with myeloid subsets and culture models. Glia 64, 1857-1868. doi: 10.1002/glia. 23023

Mertens, J., Paquola, A. C. M., Ku, M., Hatch, E., Bohnke, L., Ladjevardi, S., et al. (2015). Directly reprogrammed human neurons retain aging-associated transcriptomic signatures and reveal age-related nucleocytoplasmic defects. Cell Stem Cell 17, 705-718. doi: 10.1016/j.stem.2015.09.001

Mildner, A., Schmidt, H., Nitsche, M., Merkler, D., Hanisch, U. K., Mack, M., et al. (2007). Microglia in the adult brain arise from Ly-6ChiCCR2+ monocytes only under defined host conditions. Nat. Neurosci. 10, 1544-1553. doi: 10.1038/ nn2015

Mizee, M. R., Miedema, S. S., Van Der Poel, M., Schuurman, K. G., Van Strien, M. E., Melief, J., et al. (2017). Isolation of primary microglia from the human post-mortem brain: effects of ante- and post-mortem variables. Acta Neuropathol. Commun. 5:16. doi: 10.1186/s40478-017-0418-8

Monif, M., Reid, C. A., Powell, K. L., Smart, M. L., and Williams, D. A. (2009). The $\mathrm{P} 2 \mathrm{X} 7$ receptor drives microglial activation and proliferation: a trophic role for P2X7R pore. J. Neurosci. 29, 3781-3791. doi: 10.1523/JNEUROSCI.5512-08. 2009

Montagne, A., Barnes, S. R., Sweeney, M. D., Halliday, M. R., Sagare, A. P., Zhao, Z., et al. (2015). Blood-brain barrier breakdown in the aging human hippocampus. Neuron 85, 296-302. doi: 10.1016/j.neuron.2014.12.032

Muffat, J., Li, Y., Yuan, B., Mitalipova, M., Omer, A., Corcoran, S., et al. (2016). Efficient derivation of microglia-like cells from human pluripotent stem cells. Nat. Med. 22, 1358-1367. doi: 10.1038/nm.4189

Nagai, A., Nakagawa, E., Hatori, K., Choi, H. B., Mclarnon, J. G., Lee, M. A., et al. (2001). Generation and characterization of immortalized human microglial cell lines: expression of cytokines and chemokines. Neurobiol. Dis. 8, 1057-1068. doi: 10.1006/nbdi.2001.0437

Najafi, A. R., Crapser, J., Jiang, S., Ng, W., Mortazavi, A., West, B. L., et al. (2018). A limited capacity for microglial repopulation in the adult brain. Glia 66, 2385-2396. doi: 10.1002/glia.23477

Nayak, D., Roth, T. L., and Mcgavern, D. B. (2014). Microglia development and function. Annu. Rev. Immunol. 32, 367-402. doi: 10.1146/annurev-immunol032713-120240

Nikodemova, M., and Watters, J. J. (2012). Efficient isolation of live microglia with preserved phenotypes from adult mouse brain. J. Neuroinflammation 9:147. doi: 10.1186/1742-2094-9-147

Niraula, A., Sheridan, J. F., and Godbout, J. P. (2017). Microglia priming with aging and stress. Neuropsychopharmacology 42, 318-333. doi: 10.1038/npp. 2016.185

Njie, E. G., Boelen, E., Stassen, F. R., Steinbusch, H. W., Borchelt, D. R., and Streit, W. J. (2012). Ex vivo cultures of microglia from young and aged rodent brain reveal age-related changes in microglial function. Neurobiol. Aging 33, 195 e191-e112. doi: 10.1016/j.neurobiolaging.2010.05.008

Norden, D. M., and Godbout, J. P. (2013). Review: microglia of the aged brain: primed to be activated and resistant to regulation. Neuropathol. Appl. Neurobiol. 39, 19-34. doi: 10.1111/j.1365-2990.2012.01306.x

Noto, D., Sakuma, H., Takahashi, K., Saika, R., Saga, R., Yamada, M., et al. (2014). Development of a culture system to induce microglia-like cells from haematopoietic cells. Neuropathol. Appl. Neurobiol. 40, 697-713. doi: 10.1111/ nan. 12086 
Ohgidani, M., Kato, T. A., and Kanba, S. (2015). Introducing directly induced microglia-like (iMG) cells from fresh human monocytes: a novel translational research tool for psychiatric disorders. Front. Cell Neurosci. 9:184. doi: 10.3389/ fncel.2015.00184

Ohgidani, M., Kato, T. A., Setoyama, D., Sagata, N., Hashimoto, R., Shigenobu, K., et al. (2014). Direct induction of ramified microglia-like cells from human monocytes: dynamic microglial dysfunction in Nasu-Hakola disease. Sci. Rep. 4:4957. doi: 10.1038/srep04957

Olah, M., Patrick, E., Villani, A. C., Xu, J., White, C. C., Ryan, K. J., et al. (2018), A transcriptomic atlas of aged human microglia. Nat. Commun. 9:539. doi: 10.1038/s41467-018-02926-5

Olah, M., Raj, D., Brouwer, N., De Haas, A. H., Eggen, B. J., Den Dunnen, W. F., et al. (2012). An optimized protocol for the acute isolation of human microglia from autopsy brain samples. Glia 60, 96-111. doi: 10.1002/glia.21251

O’Neil, S. M., Witcher, K. G., Mckim, D. B., and Godbout, J. P. (2018). Forced turnover of aged microglia induces an intermediate phenotype but does not rebalance CNS environmental cues driving priming to immune challenge. Acta Neuropathol. Commun. 6:129. doi: 10.1186/s40478-018-0636-8

Oosterhof, N., Kuil, L. E., Van Der Linde, H. C., Burm, S. M., Berdowski, W., Van Ijcken, W. F. J., et al. (2018). Colony-Stimulating Factor 1 Receptor (CSF1R) regulates microglia density and distribution, but not microglia differentiation in vivo. Cell Rep. 24, 1203-1217 e1206. doi: 10.1016/j.celrep.2018.06.113

Pandya, H., Shen, M. J., Ichikawa, D. M., Sedlock, A. B., Choi, Y., Johnson, K. R., et al. (2017). Differentiation of human and murine induced pluripotent stem cells to microglia-like cells. Nat. Neurosci. 20, 753-759. doi: 10.1038/nn.4534

Park, M. J., Park, H. S., You, M. J., Yoo, J., Kim, S. H., and Kwon, M. S. (2019). Dexamethasone induces a specific form of ramified dysfunctional microglia. Mol. Neurobiol. 56, 1421-1436. doi: 10.1007/s12035-018-1156-z

Patterson, S. L. (2015). Immune dysregulation and cognitive vulnerability in the aging brain: interactions of microglia, IL-1beta, BDNF and synaptic plasticity. Neuropharmacology 96, 11-18. doi: 10.1016/j.neuropharm.2014.12.020

Perry, V. H., and Holmes, C. (2014). Microglial priming in neurodegenerative disease. Nat. Rev. Neurol. 10, 217-224. doi: 10.1038/nrneurol.2014.38

Potthoff, M. J., and Olson, E. N. (2007). MEF2: a central regulator of diverse developmental programs. Development 134, 4131-4140. doi: 10.1242/dev. 008367

Prinz, M., Jung, S., and Priller, J. (2019). Microglia biology: one century of evolving concepts. Cell 179, 292-311. doi: 10.1016/j.cell.2019.08.053

Raj, D. D., Jaarsma, D., Holtman, I. R., Olah, M., Ferreira, F. M., Schaafsma, W., et al. (2014). Priming of microglia in a DNA-repair deficient model of accelerated aging. Neurobiol. Aging 35, 2147-2160. doi: 10.1016/j. neurobiolaging.2014.03.025

Raj, D. D., Moser, J., Van Der Pol, S. M., Van Os, R. P., Holtman, I. R., Brouwer, N., et al. (2015). Enhanced microglial pro-inflammatory response to lipopolysaccharide correlates with brain infiltration and blood-brain barrier dysregulation in a mouse model of telomere shortening. Aging Cell 14, 10031013. doi: 10.1111/acel.12370

Rawji, K. S., Young, A. M. H., Ghosh, T., Michaels, N. J., Mirzaei, R., Kappen, J., et al. (2020). Niacin-mediated rejuvenation of macrophage/microglia enhances remyelination of the aging central nervous system. Acta Neuropathol. 139, 893-909. doi: 10.1007/s00401-020-02129-7

Reu, P., Khosravi, A., Bernard, S., Mold, J. E., Salehpour, M., Alkass, K., et al. (2017). The lifespan and turnover of microglia in the human brain. Cell Rep. 20, 779-784. doi: 10.1016/j.celrep.2017.07.004

Rezai-Zadeh, K., Gate, D., and Town, T. (2009). CNS infiltration of peripheral immune cells: D-Day for neurodegenerative disease? J. Neuroimmune Pharmacol. 4, 462-475. doi: 10.1007/s11481-009-9166-2

Ryan, K. J., White, C. C., Patel, K., Xu, J., Olah, M., Replogle, J. M., et al. (2017). A human microglia-like cellular model for assessing the effects of neurodegenerative disease gene variants. Sci. Transl. Med. 9:eaai7635. doi: 10. 1126/scitranslmed.aai7635

Safaiyan, S., Kannaiyan, N., Snaidero, N., Brioschi, S., Biber, K., Yona, S., et al. (2016). Age-related myelin degradation burdens the clearance function of microglia during aging. Nat. Neurosci. 19, 995-998. doi: 10.1038/nn. 4325

Satoh, J., and Kim, S. U. (1994). Differential expression of Lewis(x) and sialylLewis(x) antigens in fetal human neural cells in culture. J. Neurosci. Res. 37, 466-474. doi: 10.1002/jnr.490370406
Schmidtmayer, J., Jacobsen, C., Miksch, G., and Sievers, J. (1994). Blood monocytes and spleen macrophages differentiate into microglia-like cells on monolayers of astrocytes: membrane currents. Glia 12, 259-267. doi: 10.1002/glia.440120403

Schulz, C., Gomez Perdiguero, E., Chorro, L., Szabo-Rogers, H., Cagnard, N., Kierdorf, K., et al. (2012). A lineage of myeloid cells independent of Myb and hematopoietic stem cells. Science 336, 86-90. doi: 10.1126/science.1219179

Sellgren, C. M., Sheridan, S. D., Gracias, J., Xuan, D., Fu, T., and Perlis, R. H. (2017). Patient-specific models of microglia-mediated engulfment of synapses and neural progenitors. Mol. Psychiatry 22, 170-177. doi: 10.1038/mp.2016.220

Sevenich, L. (2018). Brain-resident microglia and blood-borne macrophages orchestrate central nervous system inflammation in neurodegenerative disorders and brain cancer. Front. Immunol. 9:697. doi: 10.3389/fimmu.2018. 00697

Shahidehpour, R. K., Higdon, R. E., Crawford, N. G., Neltner, J. H., Ighodaro, E. T., Patel, E., et al. (2021). Dystrophic microglia are associated with neurodegenerative disease and not healthy aging in the human brain. Neurobiol. Aging 99, 19-27. doi: 10.1016/j.neurobiolaging.2020.12.003

Smith, A. M., and Dragunow, M. (2014). The human side of microglia. Trends Neurosci. 37, 125-135. doi: 10.1016/j.tins.2013.12.001

Spittau, B. (2017). Aging microglia-phenotypes, functions and implications for agerelated neurodegenerative diseases. Front. Aging Neurosci. 9:194. doi: 10.3389/ fnagi.2017.00194

Spittau, B., Rilka, J., Steinfath, E., Zoller, T., and Krieglstein, K. (2015). TGFbeta1 increases microglia-mediated engulfment of apoptotic cells via upregulation of the milk fat globule-EGF factor 8. Glia 63, 142-153. doi: 10.1002/glia.22740

Stojiljkovic, M. R., Ain, Q., Bondeva, T., Heller, R., Schmeer, C., and Witte, O. W. (2019). Phenotypic and functional differences between senescent and aged murine microglia. Neurobiol. Aging 74, 56-69. doi: 10.1016/j.neurobiolaging. 2018.10.007

Streit, W. J., Braak, H., Xue, Q. S., and Bechmann, I. (2009). Dystrophic (senescent) rather than activated microglial cells are associated with tau pathology and likely precede neurodegeneration in Alzheimer's disease. Acta Neuropathol. 118, 475-485. doi: 10.1007/s00401-009-0556-6

Streit, W. J., Sammons, N. W., Kuhns, A. J., and Sparks, D. L. (2004). Dystrophic microglia in the aging human brain. Glia 45, 208-212. doi: 10.1002/glia.10319

Streit, W. J., and Xue, Q. S. (2014). Human CNS immune senescence and neurodegeneration. Curr. Opin. Immunol. 29, 93-96. doi: 10.1016/j.coi.2014.05. 005

Streit, W. J., and Xue, Q. S. (2016). Microglia in dementia with Lewy bodies. Brain Behav. Immun. 55, 191-201.

Takahashi, K., and Yamanaka, S. (2006). Induction of pluripotent stem cells from mouse embryonic and adult fibroblast cultures by defined factors. Cell 126, 663-676. doi: 10.1016/j.cell.2006.07.024

Takahashi, Y., Yu, Z., Sakai, M., and Tomita, H. (2016). Linking activation of microglia and peripheral monocytic cells to the pathophysiology of psychiatric disorders. Front. Cell Neurosci. 10:144. doi: 10.3389/fncel.2016.00144

Tamashiro, T. T., Dalgard, C. L., and Byrnes, K. R. (2012). Primary microglia isolation from mixed glial cell cultures of neonatal rat brain tissue. J. Vis. Exp. 66:e3814. doi: 10.3791/3814

Tichauer, J. E., Flores, B., Soler, B., Eugenin-Von Bernhardi, L., Ramirez, G., and Von Bernhardi, R. (2014). Age-dependent changes on TGFbetal Smad3 pathway modify the pattern of microglial cell activation. Brain Behav. Immun. 37, 187-196. doi: 10.1016/j.bbi.2013.12.018

Timmerman, R., Burm, S. M., and Bajramovic, J. J. (2018). An overview of in vitro methods to study microglia. Front. Cell Neurosci. 12:242. doi: 10.3389/fncel. 2018.00242

Trias, E., Beilby, P. R., Kovacs, M., Ibarburu, S., Varela, V., Barreto-Nunez, R., et al. (2019). Emergence of microglia bearing senescence markers during paralysis progression in a rat model of inherited ALS. Front. Aging Neurosci. 11:42. doi: 10.3389/fnagi.2019.00042

Varvel, N. H., Grathwohl, S. A., Baumann, F., Liebig, C., Bosch, A., Brawek, B., et al. (2012). Microglial repopulation model reveals a robust homeostatic process for replacing CNS myeloid cells. Proc. Natl. Acad. Sci. U.S.A. 109, 18150-18155. doi: 10.1073/pnas.1210150109

Varvel, N. H., Neher, J. J., Bosch, A., Wang, W., Ransohoff, R. M., Miller, R. J., et al. (2016). Infiltrating monocytes promote brain inflammation and exacerbate neuronal damage after status epilepticus. Proc. Natl. Acad. Sci. U.S.A. 113, E5665-E5674. doi: 10.1073/pnas.1604263113 
Villa, A., Gelosa, P., Castiglioni, L., Cimino, M., Rizzi, N., Pepe, G., et al. (2018). Sex-specific features of microglia from adult mice. Cell Rep. 23, 3501-3511. doi: 10.1016/j.celrep.2018.05.048

von Bernhardi, R., Cornejo, F., Parada, G. E., and Eugenin, J. (2015). Role of TGFbeta signaling in the pathogenesis of Alzheimer's disease. Front. Cell Neurosci. 9:426. doi: 10.3389/fncel.2015.00426

von Bernhardi, R., and Ramirez, G. (2001). Microglia-astrocyte interaction in Alzheimer's disease: friends or foes for the nervous system? Biol. Res. 34, 123-128. doi: 10.4067/s0716-97602001000200017

Wake, H., Moorhouse, A. J., Miyamoto, A., and Nabekura, J. (2013). Microglia: actively surveying and shaping neuronal circuit structure and function. Trends Neurosci. 36, 209-217. doi: 10.1016/j.tins.2012.11.007

Walker, D. G., and Lue, L. F. (2013). Understanding the neurobiology of CD200 and the CD200 receptor: a therapeutic target for controlling inflammation in human brains? Future Neurol. 8. doi: 10.2217/fnl.13.14

Wynne, A. M., Henry, C. J., Huang, Y., Cleland, A., and Godbout, J. P. (2010). Protracted downregulation of CX3CR1 on microglia of aged mice after lipopolysaccharide challenge. Brain Behav. Immun. 24, 1190-1201. doi: 10. 1016/j.bbi.2010.05.011

Ximerakis, M., Lipnick, S. L., Innes, B. T., Simmons, S. K., Adiconis, X., Dionne, D., et al. (2019). Single-cell transcriptomic profiling of the aging mouse brain. Nat. Neurosci. 22, 1696-1708. doi: 10.1038/s41593-019-0491-3

Yang, Q., Wang, G., and Zhang, F. (2020). Role of peripheral immune cellsmediated inflammation on the process of neurodegenerative diseases. Front. Immunol. 11:582825. doi: 10.3389/fimmu.2020.582825

Yona, S., Kim, K. W., Wolf, Y., Mildner, A., Varol, D., Breker, M., et al. (2013). Fate mapping reveals origins and dynamics of monocytes and tissue macrophages under homeostasis. Immunity 38, 79-91. doi: 10.1016/j.immuni.2012.12.001
You, M. J., Rim, C., Kang, Y. J., and Kwon M. S. (2021). A new method for obtaining bankable and expandable adult-like microglia in mice. J of Neuroinflamm. 18:294. doi: 10.1186/s12974-021-02351-4

Yu, H. M., Zhao, Y. M., Luo, X. G., Feng, Y., Ren, Y., Shang, H., et al. (2012). Repeated lipopolysaccharide stimulation induces cellular senescence in BV2 cells. Neuroimmunomodulation 19, 131-136. doi: 10.1159/00033 0254

Zuiderwijk-Sick, E. A., Van Der Putten, C., Bsibsi, M., Deuzing, I. P., De Boer, W., Persoon-Deen, C., et al. (2007). Differentiation of primary adult microglia alters their response to TLR8-mediated activation but not their capacity as APC. Glia 55, 1589-1600. doi: 10.1002/glia.20572

Conflict of Interest: The authors declare that the research was conducted in the absence of any commercial or financial relationships that could be construed as a potential conflict of interest.

Publisher's Note: All claims expressed in this article are solely those of the authors and do not necessarily represent those of their affiliated organizations, or those of the publisher, the editors and the reviewers. Any product that may be evaluated in this article, or claim that may be made by its manufacturer, is not guaranteed or endorsed by the publisher.

Copyright (c) 2022 Yoo and Kwon. This is an open-access article distributed under the terms of the Creative Commons Attribution License (CC BY). The use, distribution or reproduction in other forums is permitted, provided the original author(s) and the copyright owner(s) are credited and that the original publication in this journal is cited, in accordance with accepted academic practice. No use, distribution or reproduction is permitted which does not comply with these terms. 